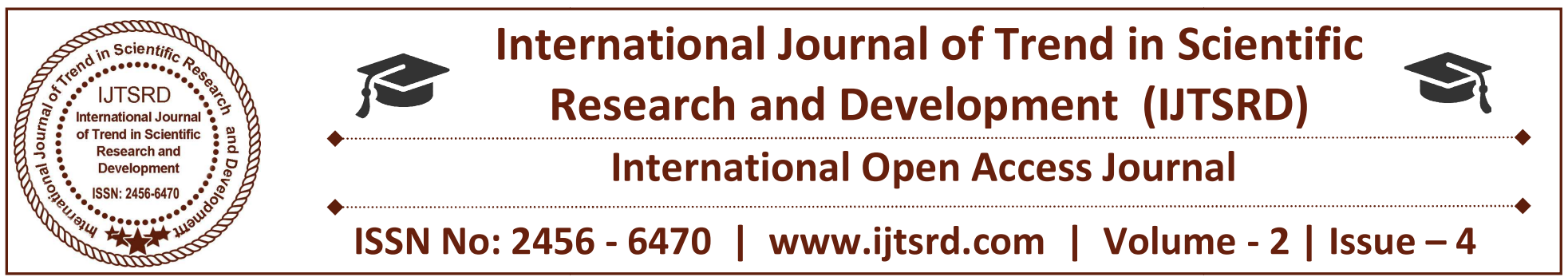

\title{
ZETA Converter for Speed Control of Electronically Commutated BLDC Motor
}

\author{
Kirti B. Nagne ${ }^{1}$, Dr. Harikumar Naidu ${ }^{2}$ \\ ${ }^{1}$ Student, ${ }^{1}$ HOD \\ Department of Electrical Engineering, TGPCET College, \\ Maharashtra ,India
}

\begin{abstract}
A Power Factor Correction (PFC) and sensor less speed control of BLDC (Brushless DC) motor using zeta converter is presented. Zeta converter is a fourthorder DC-DC converter made up of two inductors and two capacitors and capable of operating in either stepup or stepdown mode. The PFC is achieved by zeta converter. Sensor less speed control of BLDC motor is achieved and the cost and wiring of sensors are reduced. A MATLAB/ Simulink environment is used to simulate the developed model to achieve a wide range of speed control with high $\mathrm{PF}$ (Power Factor) and improved PQ (Power Quality) at the supply.
\end{abstract}

Keywords: zeta converter, Brushless Direct Current (BLDC) Motor, Power Factor Corrected (PFC), Power Quality.

\section{INTRODUCTION}

The fundamental qualities of a Permanent magnet brushless DC motor (PMBLDCM) such as wide speed range, high efficiency, rugged construction and ease of control make it suitable for air conditioning compressor application and other household application such as fan, water pump, mixers, etc. The BLDC motor not only used in household application but also these are suitable for other application such as computer disc drives, automobile starter, automobile wipers, medical equipment and many other industrial tools.

Brushless DC motors are recommended for an many applications due to the absence of mechanical commutator. It causes less need maintenance and low EMI problem. Brushless DC motor is more energy efficient than brushed DC-motors. The Brushless DC motor is smaller because its body has less heat to dissipate. It is applicable in many household appliances. Electronically commutated motors are different from other motors like brushless DC motors. In brush-type motors; commutation is done with a commutator and brushes. In brushless motor with an electronically commutated, it is achieved by switching electronics. It obtains information on the position of the rotor by means of sensors with the help of microprocessor. Electronic commutation is achieved by using a three phase voltage source inverter (VSI). International concern of power quality (PQ) problems and pollution has prompted the use of power factor correction converters with a permanent magnet brushless DC motors (PMBLDCM) for numerous low power applications. Since, the Brushless DC motor is the ideal choice for the applications that require high reliability, high efficiency, low maintenance and high power-to-volume ratio. Since it does not have any brushes to wear out and replace, generally speaking, BLDC motor is considered to be a high performance motor that is capable of providing large amounts of torque and speed performance curve characteristics. When operated in rated conditions, the life expectancy is over 10000 hours. For long term applications, this can be a tremendous benefit. These PMBLDCMs are fed from single phase $\mathrm{AC}$ mains through diode bridge rectifier (DBR) followed by a DC capacitor. However, this will results in pulsed AC current which will affect the power factor results in power quality disturbances(PQ). This is due to uncontrolled charging of the DC capacitor leading to peak value higher than the amplitude of the fundamental input 
current at $\mathrm{AC}$ mains. In order to drive the PMBLDC motor with power quality improvement it needs PFC converter topology among various available topologies [5],[6]. The basic DC-DC converter topologies. using Buck - converter, Boost converter and Buck - Boost converter have their intrinsic limitations when used for active power factor correction along with voltage regulation purposes .In common PFC converters a front end boost converter for PFC and a flyback or forward converter as second state for voltage control. Among the new classes of DC-DC converters CUK, SEPIC and Zeta, in the proposed model a Zeta converter is used for active PFC and voltage regulation having advantages of being naturally isolated structure, can operate as both step up/ down voltage converter and having only one stage processing for both voltage regulation and PFC has reported in literature.

\subsection{OVERVIEW OF DC-DC CONVERTER}

There are various DC-DC converter are available but this paper gives the performance of ZETA converter for controlling the speed of BLDC motor.

\subsection{BLOCK DIAGRAM DISCRIPTION}

\section{A Zeta converter is a fourth-order DC-} DC converter made up of two inductors and two capacitors and capable of operating in either step-up or step-down mode. The proposed scheme for the Brushless motor drive fed by a Zeta based PFC converter operating in DICM mode is shown in Fig.1 The front end Zeta DC-DC converter maintains the DC link voltage to a set reference value. Switch of the Zeta converter is to be operated at high switching frequency for effective control and small size of components like inductors. A high frequency MOSFET of suitable rating is used in the front end converter for its high frequency operation whereas an IGBT's (Insulated Gate Bipolar Transistor) are used in the VSI for low frequency operation. The proposed scheme maintains high power factor and low THD of the $\mathrm{AC}$ source current while controlling rotor speed equal to the set reference speed. A voltage follower approach is used for the control of Zeta DC-DC converter operating in DICM.

The DC link voltage is controlled by a single voltage sensor. Vdc (sensed DC link voltage) is compared with $\mathrm{Vdc}^{*}$ (reference voltage) to generate an error signal which is the difference of $\mathrm{Vdc}^{*}$ and $\mathrm{Vdc}$. The error signal is given to a PI (Proportional Integral) controller to give a controlled output. Finally, the controlled output is compared with the high frequency saw tooth signal to generate PWM (Pulse Width Modulation) pulse for the MOSFET of the Zeta converter.

Two stage PFC converters are widely in practice in which first stage is used for the power factor correction which is preferably a boost converter and second stage for voltage regulation which can be any converter topology depending upon the requirement. This two-stage topology is complex, results in higher cost and more losses. Hence a single stage Zeta converter is proposed which is used for DC link voltage control, power factor correction and bucking and boosting the voltage. It is a naturally isolated structure. ZETA converter is designed to control using a PI controller and the corresponding output response is simulated using MATLAB software. Also, the response of ZETA converter, when it is subjected to line and load variations is simulated. The proposed idea presents the study of the Zeta converter operating in continuous conduction mode for power factor correction.

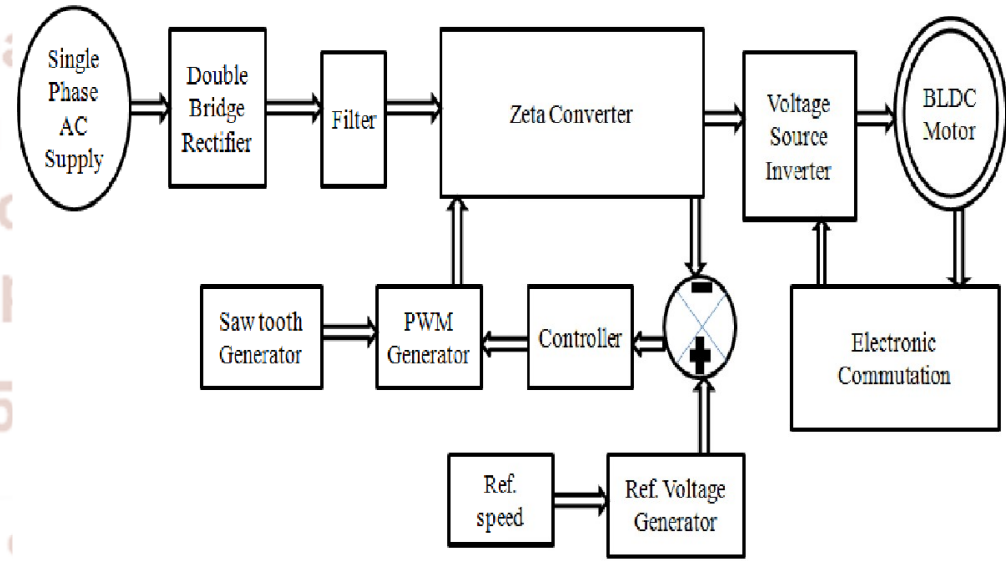

Fig. 1 block diagram of ZETA converter

\section{ZETA CONVERTER}

The Zeta converter has the capability of getting low or high voltage of output referred to the input value. This converter offers high efficiency compared to the SEPIC Converter and synchronous rectification can be easily implemented in this converter.

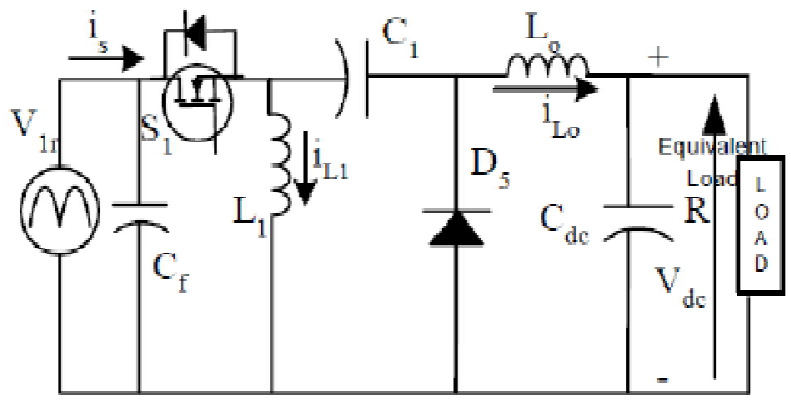

Fig -2: Circuit diagram of Zeta Converter. 
This converter operates in three modes and are as follows Mode 1 : The switch ' $\mathrm{S}$ ' is turned $\mathrm{ON}$. The source energy is transferred to the inductor L1 and output inductor $\mathrm{L} 0$ through capacitor $\mathrm{C} 1$ in turn the iL0, iL1 are increases linearly. During this mode the output voltage is in DC value. Mode 2 : The switch ' $\mathrm{S}$ ' is turned OFF. The diode $\mathrm{D}$ starts conducting in this mode. The energy stored in the inductor L1 and L0 starts to supply to the output or load, meanwhile the capacitor Cdc maintains the voltage across the load. Mode 3 : This is freewheeling mode until the start of new cycle, in this mode neither switch ' $S$ ' nor diode ' $\mathrm{D}$ ' conducts. The voltage across L1 and L0 are zero but their currents are constant until the new switching cycle begins.

\section{OPERATION OF ISOLATED PFC ZETA CONVERTER}

This converter is the latest type of single-stage input current shapers. It also uses single switching device and inherently provides an overload, short circuit, and inrush current protections. Since zeta converters behave as a resistive load to input AC mains, this converters are also called resistance emulators. Zeta converter is fourth order converters that can step down or step up the input voltage. The ZETA converter also have a series capacitor sometimes called a flying capacitor and two inductors. The ZETA converter topology gives a positive output voltage from an input voltage.

The Zeta converter has many advantages, such as buck-boost capability, and continuous output current, input to output DC insulation, so it can be used in high reliability system. This topology offers high efficiency, especially by using the synchronous rectification. The synchronous rectification can be easily implemented in this converter, because this topology, unlike the SEPIC converter, uses a low-side rectifier. The equivalent circuit of the Zeta converter is shown in Fig.3

\section{PROPOSED PFC CONVERTER OF PMBLDC MOTOR}

Fig.1 shows the proposed scheme of speed control via voltage control of dc link voltage as an equivalent to reference speed. The PMBLDC motor rotor position signals are sensed by Hall-effect sensors which is used by electronic commutator to generate switching sequence for the VSI feeding the PMBLDC motor. The Zeta DC-DC converter controls the dc link voltage using capacitive energy transfer by controlling duty cycle (D) of the zeta converter. For fast control and high switching frequency is used, Metal oxide field effect transistors (MOSFET) is employed as the switching device. The VSI fed PMBLDC motor uses switching device as IGBTs to reduce the switching stress, as

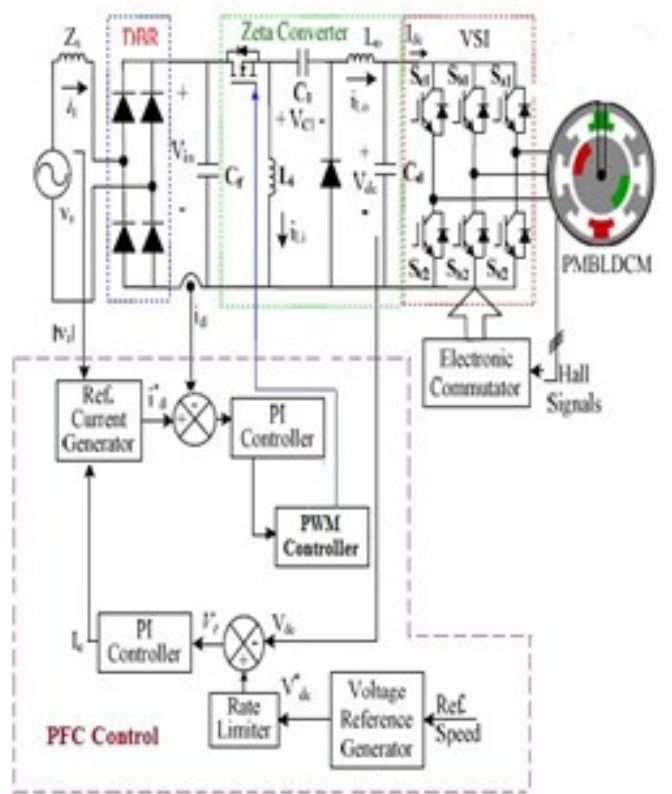

\section{Fig.1 Proposed Zeta converter for PMBLDC motor drive}

multiplier approach with current control loop inside the speed control loop for continuous-conductionmode operation of the converter. The control loop starts with comparing sensed DC link voltage (Vdc) and reference voltage $\left(\mathrm{Vdc}^{*}\right)$ equivalent to the reference speed gives voltage error (Ve). This voltage error (Ve) through a proportional Integral controller(PI) gives the modulating control signal Ic. This signal Ic is multiplied with unit template of ac voltage to give the reference input current $\left(\mathrm{Id}^{*}\right)$. This reference current $\left(\mathrm{Id}^{*}\right)$ is compared with actual input current (Id) which is sensed after the DBR. The obtained current error (Ie) is passes through another Proportional-Integral controller(PI). The resultant current error is amplified and compared with saw tooth carrier wave of fixed frequency (fs) to generate pulse width modulation PWM pulse for the MOSFET of the Zeta converter. For the control of current to PMBLDCM through VSI during the step change of the reference voltage due to the change in the reference speed, a rate limiter is introduced, which limits the stator current of the PMBLDCM within the specified value.

\subsection{Hall Sensors}

Unlike a brushed DC motor, the commutation of a BLDC motor is controlled electronically. To rotate the 
BLDC motor, the stator windings should be energized in a sequence. It is important to know the rotor position in order to understand which winding will be energized following the energizing sequence. Rotor position is sensed using Hall effect sensors embedded into the stator. Most BLDC motors embedded into the stator on the non motor. Whenever the rotor magnetic poles pass near the Hall sensors, they give a high or low signal, indicating the $\mathrm{N}$ or $\mathrm{S}$ pole is passing near the sensors. Based on the combination of these three Hall sensor signals, the exact sequence of commutation can be determined.

\subsection{Advantages of ZETA converter}

1. It is a buck-boost type converter. It means you can step up the voltage and step down as well.

2. It provides better efficiency and better voltage gain than the regular buck-boost converter.

3. The output voltage is positive in reference to the ground which makes the sensing circuit simple.

\subsection{Applications of BLDC motor}

The cost of the Brushless DC Motor has declined since its introduction, due to advancements in materials and design. This decrease in price, coupled with the many advantages it has over the Brush DC Motor, makes the Brushless DC Motor a popular component in many different applications

1. Heating and ventilation

2. Industrial automation

3. Motion control

4. Positioning and actuating system

5. Aero modeling

6. Cooling fan

\section{CONCLUSIONS}

The power quality improvement using the Zeta Converter has been proposed for low power applications. A variable DC voltage of VSI feeding
BLDC Motor has been used for variable speed operation. The Zeta Converter has operated in dis continuous mode. The VSI has operated in low frequency, thus reduces the switching losses.The performance of the BLDC Motor for variable speed are satisfactory.

\section{REFERENCES}

1. Nagesh Kinagi, Mahadevi Biradar Dr. M. S. Aspalli " Zeta Converter Fed BLDC Motor Drive Enhancement of Power Quality", IRJET Volume: 03 Issue: 07 , July-2016.

2. D. C. Martins, "Zeta Converter Operating in Continuous Conduction Mode Using the Unity Power Factor Technique", in Proceedings of IEE PEVSD'96, 1996, pp.7-11.

3. A.M.Dodke and R.G. Shrivastava "Controlling of Electronically Commuted Motor Drive using DCDC Cuk Converter ",IJETT, Vol. 28, No.4, Oct.2015.

4. B.CHANDRA KRISHNA, and M.NAGESWARA RAO, "Speed Control of BLDC Motor using Modified Buck Boost Converter", International Journal of Scientific Engineering and Technology Research, Vol.03, Issue.46,Dec.2014 ,pp.92849293.

5. P. Jagtap and Shubham Harane "Design and Control of Buck-Boost Converter fed Electronically commutated motor drive," in International Journal of Research in Advent Technology, Vol.4, No.4, April 2016.

6. R.Krishnan and S. Lee, "PM Brushless dc motor drive with a new power converter topology," in Proc. IEEE IAS Annu. Meeting, Oct. 1995, pp. $380-387$.

7. Bhim Singh, Vashist Bist, -A Single Sensor Based PFC Zeta Converter Fed BLDC Motor Drive for Fan Applications,\| IEEE Trans.Ind. Appl., vol.31, no. 5, pp. Oct 2012. 